\title{
APLICAÇÃO DE PARÂMETROS CONVECTIVOS PARA UM CASO DE LINHA DE INSTABILIDADE
}

\author{
Andréia Bender ${ }^{1}$, Edmilson Dias de Freitas ${ }^{1}$ \\ Laboratório de Meteorologia aplicado a Sistemas Regionais - MASTER (IAG/USP) \\ andreiabd@usp.br, efreitas@model.iag.usp.br
}

\section{RESUMO}

Este trabalho visa avaliar a aplicação de parâmetros convectivos (PC) para um caso de linha de instabilidade (LI) ocorrida sobre a Região Metropolitana de São Paulo (RMSP), com o intuito de demonstrar como o uso da modelagem numérica, utilizando o modelo BRAMS (Brazilian developments on the Regional Atmospheric Modeling System), pode contribuir principalmente com a obtenção de perfis atmosféricos, necessários para uma boa previsão das tempestades.

\section{SUMMARY}

The aim of this present work is evaluate the use of convective parameters for a squall line event occurred on Metropolitan Area of São Paulo (MASP), in order to show that atmospheric models, like BRAMS, can be used to contribute to obtain atmospheric profiles, which are required for a good prediction of storms.

\section{INTRODUÇÃO}

Uma característica das áreas urbanas como a RMSP são os problemas enfrentados durante a primavera e verão devido à ocorrência de tempestades severas (TS), comuns no final da tarde e início da noite. As LI são um exemplo de Sistemas Convectivos de Mesoescala que podem ser responsáveis por danos causados pela precipitação e vento intensos e granizo. Alguns PC capazes de identificar condições para o desenvolvimento dessas tempestades serão utilizados neste trabalho, são eles: CAPE (Energia Potencial disponível para Convecção), Índice de Levantamento (IL), Denominador do Número de Richardson Volumétrico (DNRV), Helicidade relativa à tempestade, integrada nos primeiros $3 \mathrm{~km}$ da atmosfera (HRT3), Índice de Energia-helicidade (IEH) e Parâmetro de Supercélula (SUP).

\section{MATERIAL E MÉTODOS}

Para a obtenção dos perfis atmosféricos necessário para o calculo dos PC, foi realizada uma simulação do caso de LI do dia 14/04/2008, utilizando o modelo BRAMS (FREITAS et al. 
2005). A simulação foi feita com $8 \mathrm{~km}$ de espaçamento horizontal utilizando apenas a parametrização de microfísica para a convecção, do período das $12 \mathrm{Z}$ do dia 13 até as $00 \mathrm{Z}$ do dia 15/04/2008. Os PC são definidos em Bender (2012).

\section{RESULTADOS E DISCUSSÃO}

Os resultados obtidos da simulação para o ponto mais próximo de Campo de Marte, as 00Z do dia 14 se assemelham bastante com a sondagem do mesmo horário (Figuras não apresentadas). O tipo de representação da Figura 1 nos dá a oportunidade de analisar as condições precursoras de tempestade sobre a RMSP. Neste período, os valores de CAPE são considerados como moderadamente instáveis. IL indica formação de TS na presença de um mecanismo de levantamento. DNRV possui valores acima de $20 \mathrm{~m}^{2} \mathrm{~s}^{-2}$, segundo Thompson et al. (2003) são geralmente observados em condições de TS (tornádico ou não). Enquanto o HRT3 chega a $-150 \mathrm{~m}^{2} \mathrm{~s}^{-2}$, acima de $150 \mathrm{~m}^{2} \mathrm{~s}^{-2}$ tendem a favorecer TS no hemisfério norte (HN) (MILLS \& CONQUHOUN, 1998). IEH e SUP não indicam valores favoráveis a TS e supercélulas. Valores acima de 2 são associados à alta probabilidade de ocorrência de TS para o HN, inclusive tornados (RASMUSSEN \& BLANCHARD, 1998) e SUP acima de 1 favorecem supercélulas (THOMPSON et al. 2003). Nascimento (2004) destaca que para o Hemisfério Sul, situações de TS são indicadas por valores negativos de HRT3, IEH e SUP e sugere os mesmos limiares utilizados no $\mathrm{HN}$, já que ainda não existe uma base climatológica destes PC para o Brasil.

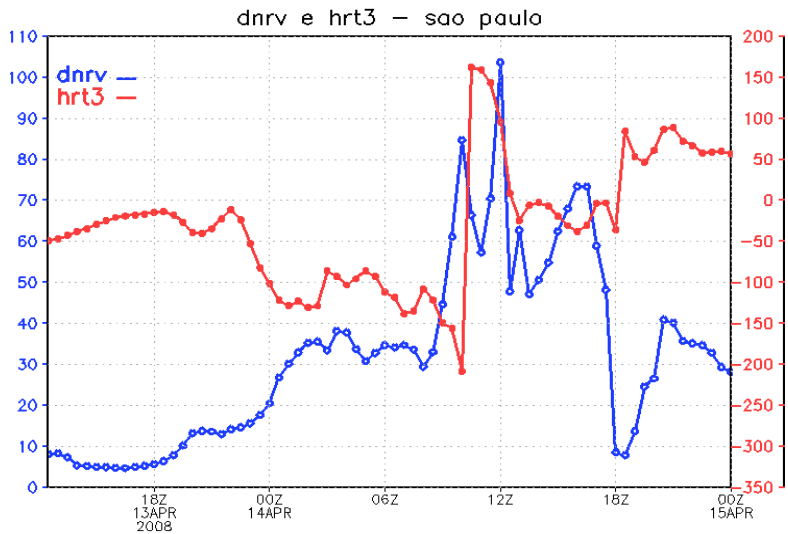

Figura 1: DNRV $\left(\mathrm{m}^{2} \mathrm{~s}^{-2}\right)$, em azul, e HRT3 $\left(\mathrm{m}^{2} \mathrm{~s}^{-2}\right)$, em vermelho, sobre Campo de Marte-SP, calculados da simulação.

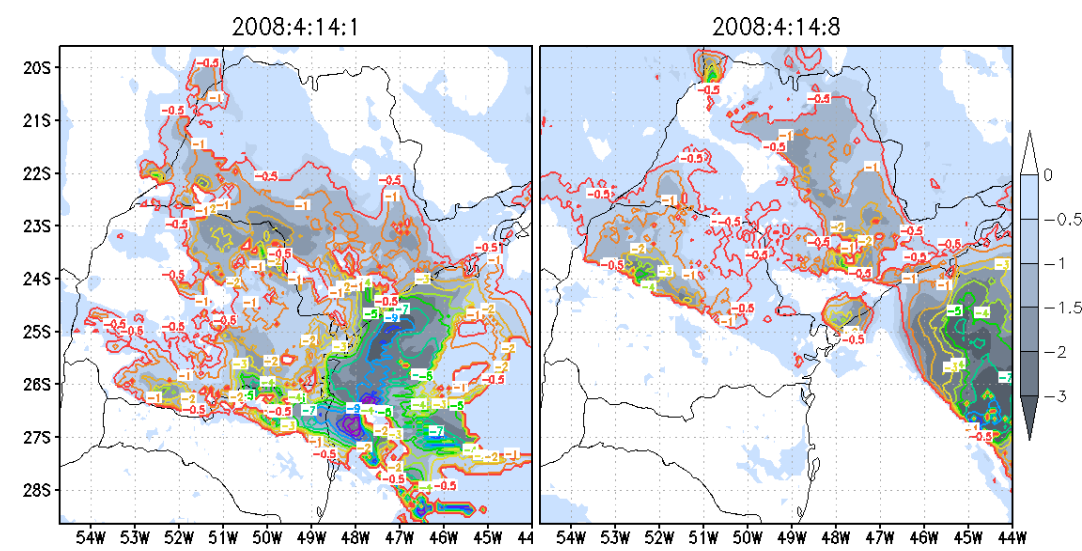

Figura 2: IEH (sombreado) e SUP (contornos), para o caso da LI às 01Z (esquerda) e 08Z (direita) de 14 de abril de 2008, calculados da simulação. 


\section{CONCLUSÕES}

Foi observado que o ambiente onde a LI se formou apresentava instabilidade e cisalhamento moderados. Os PC aparentam serem bons indicadores de TS na presença de sistemas de origem baroclínica, apresentando valores similares aos encontrados para o HN. Embora a falta de informações relativas a estas TS, como a ocorrência de supercélulas, granizo, entre outros, dificultam a interpretação. Entretanto, é possível verificar que o uso de PC derivados das informações fornecidas pelos modelos meteorológicos pode cobrir com certa qualidade as áreas em que não existem informações em superfície e ar superior, como apresenta a Figura 2.

\section{AGRADECIMENTOS}

Os autores agradecem Ao CNPq e CAPES pelo apoio financeiro.

\section{BIBLIOGRAFIA}

Bender, A. Eventos de Tempo Severo associados às linhas de Instabilidade sobre o Estado de São Paulo. 105pp. Dissertação - Instituto de Astronomia, Geofísica e Ciências Atmosféricas, Universidade de São Paulo, São Paulo, 2012.

Freitas, S. R.; Longo, K. M.; Silva Dias, M. A. F.; Silva Dias, P. L.; Chatfield, R.; Prins, E.; Artaxo, P. E.; Grell, G.; Recuero, F. S.: Monitoring the Transport of Biomass Burning Emissions in South America. Environmental Fluid Mechanics, 5, 135-167, 2005.

Mills, G. A. \& Conquhoun, J. R. Objective Prediction of Severe Thunderstorm Environments: Preliminary Results Linking a Decision Tree with an Operational Regional NWP Model. Weather and Forecasting, 13, 1078-1092, 1998.

Nascimento, E. L. Previsão de Tempestades Severas utilizando-se Parâmetros Convectivos e Modelos de Mesoescala: Uma Estratégia Operacional Adotável no Brasil? Revista Brasileira de Meteorologia, 2004.

Rasmussen, E. \& Blanchard, D. O. A Baseline Climatology of Sounding-derived Supercell and Tornado Forecast Parameters. Weather and Forecasting, v.13, p.1148-1164, 1998.

Thompson, R. L.; Edwards, R.; Hart, J. A.; Elmore, K. L.; Markowski, P. Close Proximity Soundings Within Supercell Environments Obtained from the Rapid Update Cycle. Weather and Forecasting, v. 18, p. 1243-1261, 2003. 